\title{
Effectiveness of recreational divers for monitoring sea turtle populations
}

\author{
Jessica L. Williams ${ }^{1,2,3,4, *}$, Simon J. Pierce ${ }^{2,3}$, Mariana M. P. B. Fuentes ${ }^{1,4}$, \\ Mark Hamann ${ }^{1}$ \\ ${ }^{1}$ James Cook University, School of Earth and Environmental Sciences, Townsville, QLD 4811, Australia \\ ${ }^{2}$ Marine Megafauna Foundation, Tofo Beach, Inhambane, Mozambique \\ ${ }^{3}$ All Out Africa Research Unit, Marine Research Centre, PO Box 153, Lobamba, Swaziland \\ ${ }^{4}$ ARC Centre of Excellence for Coral Reef Studies, James Cook University, Townsville, QLD 4811, Australia
}

\begin{abstract}
Five sea turtle species, all globally threatened, are found in southern Mozambican waters. Illegal hunting of foraging turtles, nest raiding and modification of coastal habitat are assumed to affect local sea turtle populations, but a lack of capacity and resource constraints hamper monitoring and compliance activities. Enlisting the recreational SCUBA diving community to report sea turtle sightings is a potential solution for population monitoring. The effectiveness of recreational divers as monitors was tested through the review of 2 approaches: the use of a routine dive logbook with sightings, and data from a dedicated survey. These approaches provided 37 consecutive months of data between 2008 and 2011 from dive sites in Inhambane Province, Mozambique. A total of 317 sightings of loggerhead Caretta caretta, green Chelonia mydas, hawksbill Eretmochelys imbricata and unidentified turtle species were reported from 918 dives. While the dedicated survey collected more detailed behavioural data (e.g. response to divers and feeding behaviour), independent logbook records provided a more robust data set for analysis of sighting trends. Useful data on sea turtle species composition, size and distribution were obtained from both approaches, although there were concerns with regard to species identification and size estimates. With refined methodology, particularly the incorporation of photographic verification of species identification, reports from divers can provide cost-effective and useful data for monitoring foraging turtle populations.
\end{abstract}

KEY WORDS: SCUBA divers $\cdot$ Citizen science $\cdot$ Marine turtle $\cdot$ Mozambique $\cdot$ Africa $\cdot$ Volunteer

\section{INTRODUCTION}

An increasing number of research programmes incorporate non-specialist members of the public as 'citizen scientists', both as an educational tool and as a cost-effective monitoring strategy (Bhattacharjee 2005, Bonney et al. 2009, Crall et al. 2011). In the marine realm, volunteer recreational divers have been involved in collection of data for biodiversity assessments and coral reef fish (Darwall \& Dulvy 1996, Hodgson 1999, Pattengill-Semmens \& Semmens 2003) and flora abundance surveys (Chou 1994,

${ }^{*}$ Corresponding author: jess@mozturtles.com
Schmitt \& Sullivan 1996). In addition to these broadly scoped programmes, volunteer divers are also involved in focal species programmes focused on seahorses (Goffredo et al. 2004), sea turtles (Bell et al. 2008b) and elasmobranchs (Hussey et al. 2011, Ward-Paige \& Lotze 2011). Although such data collection programmes are generally designed to test specific hypotheses or undertake routine monitoring, a key tenet is that participants are not required to have formal training in scientific survey techniques.

By accepting the limitations of such a tenet, the overwhelmingly appealing aspects of adopting a citi-

() The authors 2015. Open Access under Creative Commons by Attribution Licence. Use, distribution and reproduction are unrestricted. Authors and original publication must be credited. 
zen science programme can be realised. Such benefits include low cost and a potentially large unpaid workforce, allowing for monitoring over large geographic areas or temporal periods (Mumby et al. 1995, Teleki 2012). Additionally, citizen science programmes can be used as education and outreach tools to promote conservation objectives and even to engage potential funders or fund specialist research projects (Gouveia et al. 2004). Success of citizen science projects as measured through their outputs or scientific applications has been varied (Darwall \& Dulvy 1996, Van Strien et al. 2013), but has increased over time.

However, because some volunteer-based efforts are not developed with the aim of producing publishable data in mind (Paulos 2009) or, alternatively, do not result in data of suitable quality, the value of such programmes to conservation and management has been contested (Halusky et al. 1994, Mumby et al. 1995, Darwall \& Dulvy 1996). Debates centre around aspects of the inherent shortcomings of citizen science with a focus on the effectiveness and adequacy of training. One common deficiency of citizen science projects is a lack of recognition by participants of potential sources of error and associated corrective actions, due to their lack of familiarity with experimental design (Paulos 2009). Citizen scientists have also been criticised for overestimating abundance and species diversity (Foster-Smith \& Evans 2003, Uychiaoco et al. 2005), and failing to fully document observations (Roxburgh 2000, Barrett et al. 2002) or record factors such as effort (Halusky et al. 1994, Lynch et al. 2004). There have also been concerns on the reliability of taxa identification below family level (Halusky et al. 1994, Mumby et al. 1995). Comprehending both strengths and weaknesses of citizen science is essential for successfully utilising this technique (Conrad \& Hilchey 2011). To achieve effective research outcomes, the citizen science programme must be designed accounting for the capacity of its volunteer collectors and the skills required to implement its data collection method (Shirk et al. 2012, Van Strien et al. 2013). In the present paper we evaluate the utility of data collection by volunteers undertaking an in-water sea turtle monitoring project. We make recommendations to improve the design of such projects to maximise scientific value.

Monitoring of nesting sea turtles has traditionally used a large volunteer workforce (Ellis 2003). There are some long-running and well-recognised turtle projects that are based on a model that uses citizen scientists to collect most or all of their data, for example at Tortuguero in Costa Rica (Campbell \& Smith 2006) and Mon Repos in Australia (Wilson \& Tisdell
2001). In most cases, such field-based marine turtle research projects are overseen by trained researchers and implemented by trained volunteers or staff, as in programs in Florida and North Carolina, USA (Bradford \& Israel 2004, Cornwell \& Campbell 2012), and generally include quality checks on the data. Citizen science is often considered a cost-effective tool for ensuring sufficient participants to complete resourceintensive monitoring programmes, such as comprehensive nesting beach censuses (Eckert 1999, Silvertown 2009, Landry \& Taggart 2010), that would not otherwise be economically or logistically feasible.

The relative ease of land-based as opposed to ocean-based surveys means that sea turtle population estimates tend to be based on nesting surveys rather than knowledge of total population size (Bjorndal 1999, Sims et al. 2008). In-water monitoring programmes have frequently adopted physical capture techniques such as tangle netting (Seminoff et al. 2002, Eaton et al. 2008) and direct capture (rodeo) (Limpus \& Reed 1985, Ehrhart \& Ogren 1999). Some in-water sea turtle monitoring projects have used volunteers or recreational divers for data collection, but their application is often limited because these specific projects have typically been equipment intensive and require specialist training and physical skills (e.g. SCUBA, free diving and advanced animal handling skills). Although the opportunity to view sea turtles is often acknowledged as a tourist attraction on coral reefs (Schofield et al. 2006, Eaton et al. 2008), a scarce number of projects have explored this as a potential solution for collecting information and there are fewer documented projects based on noninvasive in-water citizen science for monitoring foraging turtles (e.g. Hickerson 2000, Houmeau 2007, Bell et al. 2008b).

Five sea turtle species live and nest along Mozambique's $2700 \mathrm{~km}$ coastline: loggerhead Caretta caretta, green Chelonia mydas, hawksbill Eretmochelys imbricata, leatherback Dermochelys coriacea and olive ridley turtles Lepidochelys olivacea (Louro et al. 2006). All sea turtles in Mozambique face increasing threats from fishing (including gill-netting, beach seining and trawling), direct take (fishing for sustenance and/or traditional take) and coastal habitat modification (Louro et al. 2006, Costa et al. 2007). Data on their distribution, migration and nesting areas in the country are scarce and restricted to a few locations (Costa et al. 2007). Inhambane Province, in southern Mozambique, is an emerging marine tourism destination (Pierce et al. 2010, Tibiriçá et al. 2011) and has been proposed as a potential Marine World Heritage site based on its outstanding mar- 
ine wildlife (Obura et al. 2012). However, this region also has the highest recorded levels of turtle mortality in Mozambique (Pereira et al. 2010), despite all turtle species having been legally protected from consumptive use since 1965 (Pereira et al. 2010). There is a need for baseline data to effectively manage Mozambique's turtle populations, which currently cannot be achieved through conventional means due to limited resources. The citizen science approach may be a solution to this issue.

Conscientious long-term record-keeping by recreational divers has been shown to have considerable scientific value (Goffredo et al. 2010, Ward-Paige \& Lotze 2011, Jaine et al. 2012), particularly when there are reliable records of the presence and absence of the focal species coupled with environmental data (Goffredo et al. 2004, Hussey et al. 2011, Ward-Paige et al. 2011). Divers can facilitate continuous temporal monitoring of large areas where resources and either traditional academic or government research interest are low (Goffredo et al. 2010, Lorenzo et al. 2011). Increasingly, scientists are utilising these citizen science records and personal logbooks to assess longterm trends (e.g. Lloyd et al. 2012, Jaine et al. 2012) and an increasing number of historical data sets are being recognised as a source of high quality data (Miller-Rushing et al. 2012).

Mozambique, where there are few resources available for monitoring, a long and remote coastline and limited knowledge of species abundance and distribution, presents a challenge for conservation managers. Specifically, limited contemporary nesting and thus opportunity to sample on nesting beaches creates a challenge for managers to assess the impacts and scale of direct take of nests and foraging turtles. Here, we assess foraging turtle populations in an understudied region of Mozambique by evaluating data collected from 2 different citizen science initiated monitoring programmes: (1) logbook records from a single dive operator, and (2) a dedicated survey of turtle sightings recorded by multiple staff from different dive operators and paying volunteers from a local conservation organisation. Two such pre-existing citizen science data sets were available to us, for the purpose of comparing strategies to see whether either could produce usable data. Our aim was to evaluate the results, identify issues associated with using volunteer participants and refine protocols for future studies that could benefit from the same approach. Our secondary objective was to provide the first information from in-water observations of species composition, abundance and spatio-temporal patterns of sea turtle presence from Mozambique.

\section{MATERIALS AND METHODS}

\section{Data collection}

We were provided access to 2 data sets from the Tofo dive tourism industry to review their potential scientific value for in-water sea turtle monitoring. First, there was a dive logbook/register independently established and collected by one dive centre, where the megafauna species sighted on every dive were recorded (e.g. bottlenose dolphin, humpback whale, white tip reef shark, reef and giant manta rays), regardless of presence/absence of turtles (logbook). Second, from 4 other dive centres, there was a turtle sightings survey, where divers specifically reported the presence of a turtle during a dive (dedicated survey), which was initiated by a marine volunteer project. Whilst the dedicated survey was intended for scientific use, the logbook was recorded without a specific purpose or at least not originally intended for scientific application.

The logbook data set covered 653 dives conducted between 19 March 2008 and 28 October 2009, and represented the majority of diving effort conducted by this dive centre (similar to Lynch et al. 2004). All staff members were involved in the data recording process. For analysis, turtle sightings were reported as a daily binary presence/absence at each dive site to avoid potential bias from individual turtles being double-counted during a single dive, or by different groups on a single day. Species and dive site were recorded, and other parameters including depth, total dive time, current strength and visibility were also reported for most dives.

Project coordinators of a marine volunteer conservation organisation initiated a dedicated survey for sea turtle sightings that took place between 2009 and 2011, using a survey protocol adapted from Bell et al. (2008b). Surveys were designed to record sea turtle sightings on a daily basis. Following a voluntary agreement by 4 dive centres (notated as dive center $\mathrm{A}, \mathrm{B}, \mathrm{C}$ and D) to participate in the monitoring programme, a briefing was provided to give instruction on methodology and data capture. A briefing on turtle species identification by the project coordinator of the marine conservation programme was provided to participating staff at each dive operation. Materials such as dichotomous keys, along with charts and information posters to assist with species identification, were also provided. Participants were encouraged to provide photographs to validate species identification. Criteria on the survey forms included date, time, location, species, behaviour and environ- 
mental characteristics (depth, water temperature and visibility). Dive centre D hosted paying volunteers from a marine conservation programme, and these volunteers participated in the dedicated survey programme. At each dive centre, one person from each trip, most frequently a divemaster, divemaster trainee or marine volunteer (at dive centre D), filled in the dedicated survey form. Dedicated survey forms were completed in accordance with group consensus of the paying volunteers (from dive centre D) or dive staff present on the dive.

\section{Site description}

All data were collected from reefs close to Tofo Beach (Praia do Tofo) $\left(-23.51^{\circ} \mathrm{S}, 35.23^{\circ} \mathrm{E}\right)$, a small seaside resort town situated in Inhambane Province, Mozambique, about $400 \mathrm{~km}$ northeast of the nation's capital, Maputo (Fig. 1). Survey reefs were located along a $40 \mathrm{~km}$ stretch of coast from $500 \mathrm{~m}$ to $15 \mathrm{~km}$ offshore. These reef habitats are rocky with low hard coral diversity. The depth of surveyed reefs ranged from 11 to $30 \mathrm{~m}$. Ocean conditions are dynamic, with underwater horizontal visibility varying from 5 to 30 m (Tibiriçá et al. 2011) and water temperature

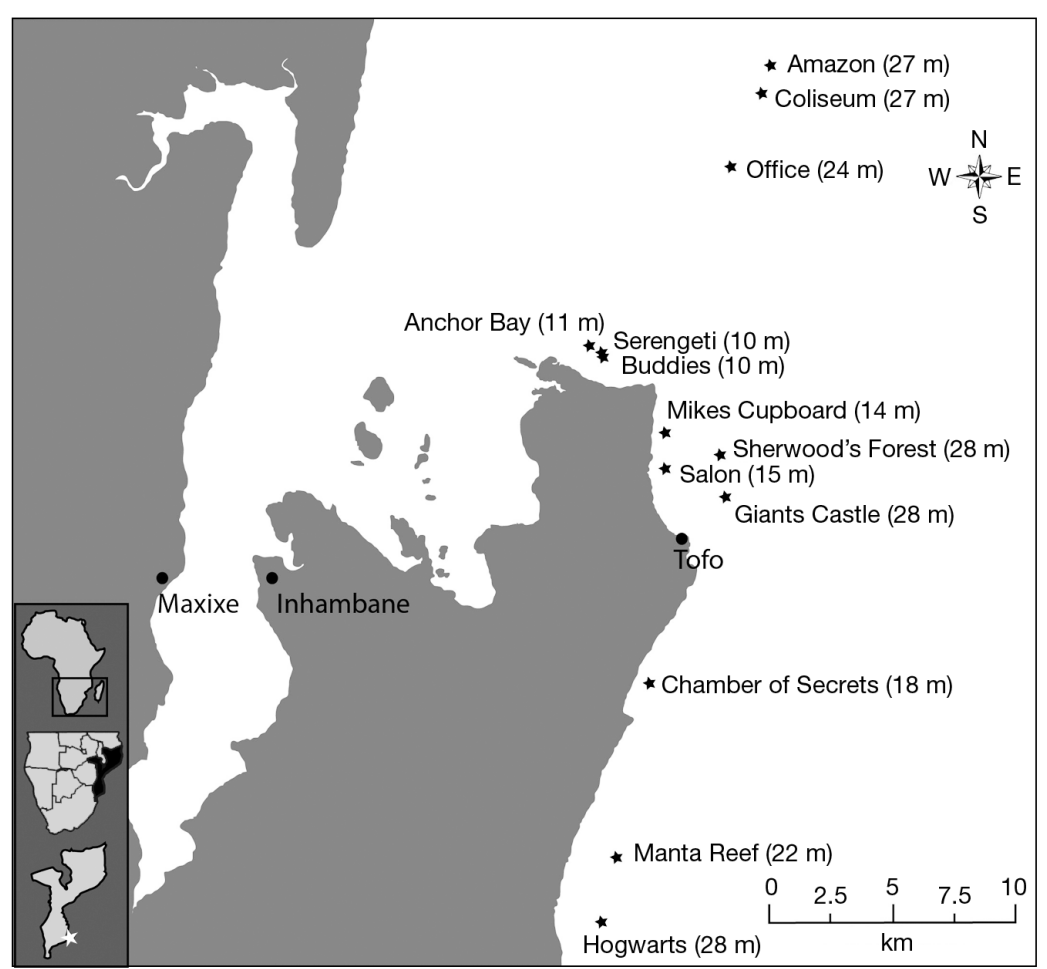

Fig. 1. Study site (Tofo Beach, Mozambique) and surveyed dive sites, with average depths in parentheses varying seasonally from a high of $30^{\circ} \mathrm{C}$ during summer months (Dec-Mar) to $16^{\circ} \mathrm{C}$ during the winter (Jul-Sep) (Rohner et al. 2013). Current strength is also variable, with stronger currents potentially affecting the search ability and coverage of divers. When weather conditions with a Beaufort sea-state of 4 or above (and swells of $2.5 \mathrm{~m}$ or above) were present, diving was prohibited for safety reasons. Cyclones occasionally occur over summer months and lead to periods where diving is not possible.

\section{Data validation and analysis}

To avoid possible data duplication within a day, or between dive groups at 1 site, only 1 record per species per day at a specific site was used in analyses. Similarly, to avoid the possibility of double-counting an individual turtle seen at different times during the same dive, we treated data as presence/absence rather than a count of individual turtles. On days with multiple encounters, only the first record of the day was included in analysis. During the 16-mo sampling period this resulted in elimination of 27 records across 24 sampling days (2 animals sighted per day, $\mathrm{n}=22 ; 3$ animals sighted, $\mathrm{n}=1 ; 4$ animals sighted, $\mathrm{n}=1$ ). This also resulted in ancillary data, such as sizes and behavior, which were discarded through this process. Minimum categories required from either the logbook or dedicated survey included date, dive site and animals sighted.

Although sightings $(\mathrm{n}=24)$ of leatherback turtles Dermochelys coriacea were recorded in the data set, these records were not considered in analyses as they were always of animals sighted at the sea surface while boats were in transit, rather than at specific dive sites.

Where possible, mean dive times and depth were calculated for each site to provide a representative measure for effort. Because dive times were recorded in the logbook data set, the probability of encountering a turtle during a dive (turtle sightings per hour) could be calculated. Differences in the characteristics of each data set meant that they could not be combined for analysis of annual and seasonal sighting trends, so intra-data set analyses were conducted to evalu- 
ate the accuracy and utility of results. Estimates exceeding $1.2 \mathrm{~m}$ for loggerhead, $1.4 \mathrm{~m}$ for green and $0.9 \mathrm{~m}$ for hawksbill turtles were classified as biologically improbable (Van Buskirk \& Crowder 1994). All length estimates were included in the analysis to demonstrate accuracy; however, it was not possible to calculate mean carapace length as observers visually estimated lengths. Inter-annual and seasonal trends could not be examined using the consecutive data sets together due to positive sighting bias in the dedicated surveys; instead, they were considered independently.

\section{RESULTS}

\section{Logbook}

Fifty-two turtle sightings were recorded during 653 dives between 19 March 2008 and 28 October 2009, equating to a sighting rate of $8.1 \%$. A mean turtlesighting rate of 0.15 turtles $\mathrm{h}^{-1}$ was calculated from the total dive effort (497.89 diving hours). The majority of sightings $(67.4 \%, \mathrm{n}=35)$ were not classified to species. For identified sightings, loggerhead turtles were the most frequently observed $(n=10)$, followed by green $(\mathrm{n}=4)$ and hawksbill turtles $(\mathrm{n}=3$; Table 1$)$. Estimates of carapace length (CL) were not recorded in the logbook data set.

Of 720 dives recorded in the logbook data set, 653 ( $91 \%$ ) entries were sufficiently complete (minimum recording standard of date, dive site and animals sighted) for use in analyses. The response rate per category was not consistent across the 2 data sets (Table 2). Response rates for date, site and depth were comparable between logbook and dedicated survey methodologies, but there was lower reporting of species, temperature and visibility categories in the logbook data set (Table 2).

Table 1. Summary of reported turtle sightings by species and data set from Tofo Beach, Mozambique. Data were summarised as daily presence/absence at a site to avoid duplicate sightings. Sightings for each data set were reported between 19 March 2008 and 28 October 2009 in the logbook and between 13 December 2009 and 22 March 2011 in the dedicated surveys. Species proportions of total sightings are given in parentheses for the logbook but do not exist for the dedicated survey data set

\begin{tabular}{|lccccc|}
\hline Data set & $\begin{array}{c}\text { Caretta } \\
\text { caretta }\end{array}$ & $\begin{array}{c}\text { Chelonia } \\
\text { mydas }\end{array}$ & $\begin{array}{c}\text { Eretmochelys } \\
\text { imbricata }\end{array}$ & Unknown & Total \\
\hline Logbook & $10(1.5 \%)$ & $4(0.6 \%)$ & $3(0.4 \%)$ & $35(5.3 \%)$ & $52(8.1 \%)$ \\
Dedicated survey & 109 & 91 & 59 & 6 & 265 \\
Total & 119 & 95 & 62 & 41 & 317 \\
\hline
\end{tabular}

Table 2. Response rates per data collection criterion according to data set (logbook, $\mathrm{n}=720$; dedicated survey, $\mathrm{n}=330$ ). Values in parentheses are no. of dives. (-) Information not requested for the respective data sheet

\begin{tabular}{|lcc|}
\hline \multirow{2}{*}{ Category } & \multicolumn{2}{c}{ Response rate (\%) } \\
\cline { 2 - 3 } & Logbook & Dedicated survey \\
\hline Date & $100(720)$ & $98(330)$ \\
Total dive time & $21(55)$ & - \\
Time of encounter & - & $94(313)$ \\
Site & $97(701)$ & $100(334)$ \\
GPS & - & $1.5(5)$ \\
Species & $10(73)$ & $97(325)$ \\
Size & - & $76(248)$ \\
Sex & - & $6(21)$ \\
Behaviour & - & $87(291)$ \\
Seas (m) & - & $17(58)$ \\
Swell (m) & - & $16(56)$ \\
Visibility (m) & $15(105)$ & $61(202)$ \\
Temperature ( $\left.{ }^{\circ} \mathrm{C}\right)$ & $11(79)$ & $66(223)$ \\
Depth $(\mathrm{m})$ & $21(155)$ & $29(98)$ \\
No. of divers in the water & $23(78)$ & - \\
Encounter duration (min) & - & $26(87)$ \\
Avoidance (Y/N) & - & $83(280)$ \\
\hline
\end{tabular}

\section{Dedicated surveys}

A total of 265 turtles were recorded across a 16-mo sampling period between 13 December 2009 and 22 March 2011. Contribution of data was not consistent between the 4 dive centres participating in the dedicated surveys ( $\mathrm{A}=49, \mathrm{~B}=64, \mathrm{C}=43, \mathrm{D}=109$ ). It was not possible to use the turtle sighting and dive records to quantify effort because overall dive effort per centre was not collected, and one dive centre (D) was a key supplier in the data collection process.

Although the dedicated survey record sheet focused on positive sightings of turtles, divers and dive centres were encouraged by volunteer project coordinators to record dives where turtles were absent. Despite the encouragement, no records were submitted of zero sightings, leading to an artificially high $100 \%$ sighting rate from this data set.

The response rate of surveys complete with enough information to include in analysis was lower ( $\mathrm{n}=265, \sim 80 \%$ ) from the dedicated survey forms $(\mathrm{n}=334)$ than from the logbook ( 91\%). There were 9 additional information categories requested in the dedicated survey forms compared to the 8 core categories in the logbook (Table 2). 
Data collectors assigned $97 \%$ of sighting records to a species. The most abundant species recorded in this data set were loggerhead, followed by green and hawksbill (Table 1). Of 265 sightings, CL was provided in $70.94 \%(n=188)$ of records. Biologically implausible overestimates were apparent in $11.7 \%$ $(n=22)$ of records, with loggerheads being the species most likely to have overestimated CL $(\mathrm{n}=16)$. A mixed size structure was evident (Fig. 2). Irrespective of species, all individuals exceeded $40 \mathrm{~cm} \mathrm{CL}$, and the most common size bin of turtles recorded was for estimated CL of 71 to $100 \mathrm{~cm}$. The largest variation in size of estimated CL was in green turtles (40 to 110 cm; Fig. 2A).

\section{Comparison between logbook and dedicated surveys}

Data from both data sets indicated that daily turtle sightings varied significantly between dive sites (2-tailed $t$-test, $t=51.33, \mathrm{df}=51, \mathrm{p}<0.001$ ). The highest sighting rates were recorded at the deeper dive sites, including Sherwood's Forest $(28 \mathrm{~m} ; 0.46 \pm$ 0.16 turtles $\left.\mathrm{h}^{-1}\right)$, Hogwarts $\left(28 \mathrm{~m}_{;} 0.22 \pm 0.22\right.$ turtles $\left.\mathrm{h}^{-1}\right)$ and Amazon $\left(27 \mathrm{~m} ; 0.22 \pm 0.10\right.$ turtles $\left.\mathrm{h}^{-1}\right)$ (Fig. 3). In addition to sightings, the frequency with wich dive centres visited the high-density turtle sites (pooled for Amazon, Hogwarts and Sherwood's) also varied from a minimum of $9.37 \%$ (of all records logged) by dive centre B to a maximum of $23.85 \%$ by dive centre $\mathrm{D}$.

\section{DISCUSSION}

\section{Using recreational divers for monitoring sea turtles}

Our study demonstrated that useful data for monitoring foraging turtles, including detected abundance, species composition, sightings distribution and population structure, can be obtained from recreational divers. However, in future studies, the importance of careful experimental design and meticulous reporting procedures should be emphasised. It is clear from the data sets we examined that ad hoc implementation and reporting by casual observers diminished the scientific value of the data sets. The data are valuable for providing basic population structure, species composition and turtle sighting rates, and although precise morphometrics such as CL were not as reliable, they could be easily improved for future studies. If dedicated surveys
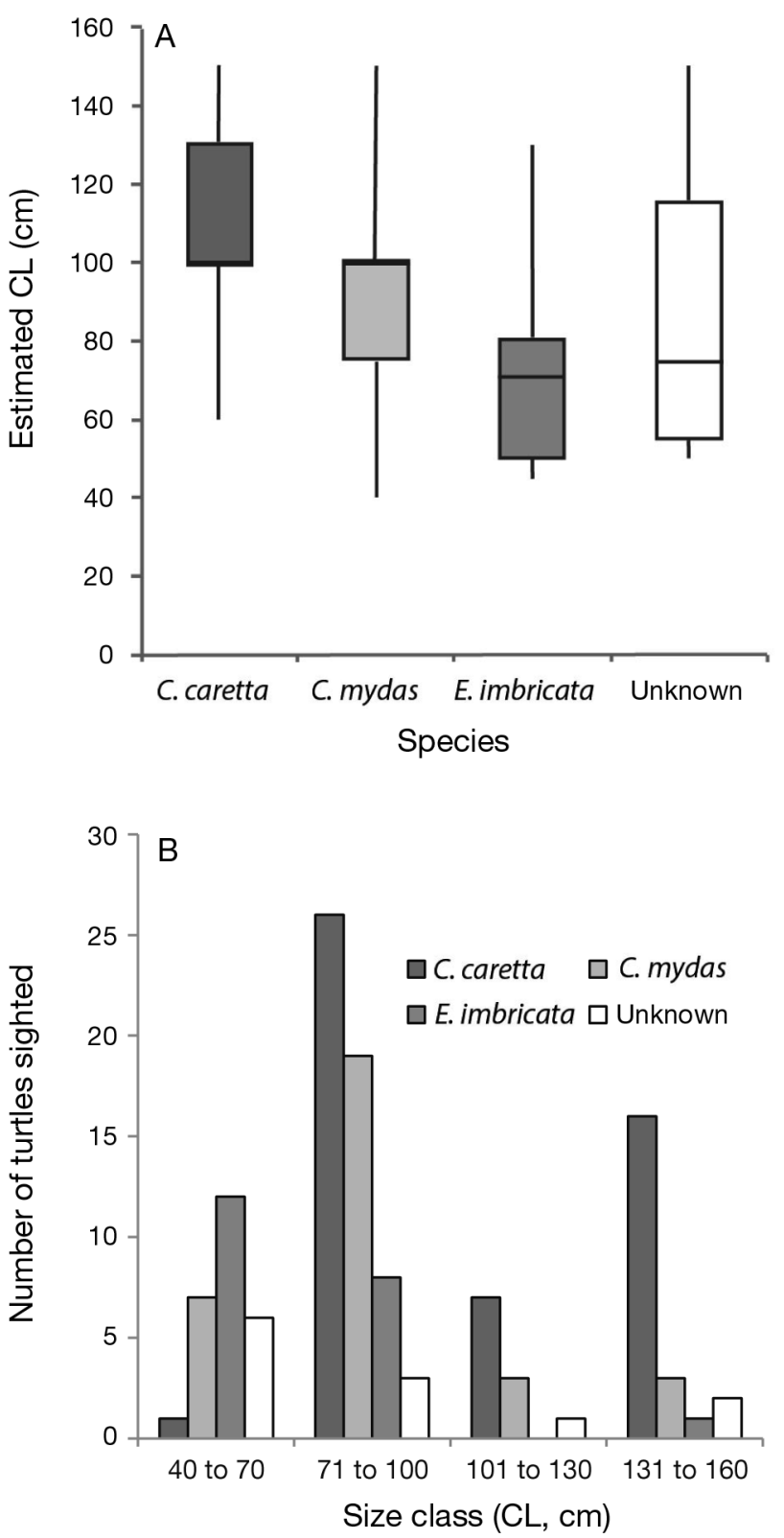

Fig. 2. Size of turtles sighted in the course of the dedicated surveys ( $\mathrm{n}=115$ ) for Caretta caretta, Chelonia mydas, Eretmochelys imbricata and unknown species. (A) Linear descriptive statistics from dedicated survey data showing the range and spread of carapace length (CL) data between the 25th and 75th percentiles, with bold line representing the median. (B) Count and distribution of estimated turtle CL according to species, including estimates suspected to exceed biological maximums $(n=22)$

were reported more regularly and coupled with photo-identification records, these data would allow for examination of seasonality, individual site residency, population models and long-term sighting trends. With some modifications to survey structure, training and reporting, the involvement of the diving 


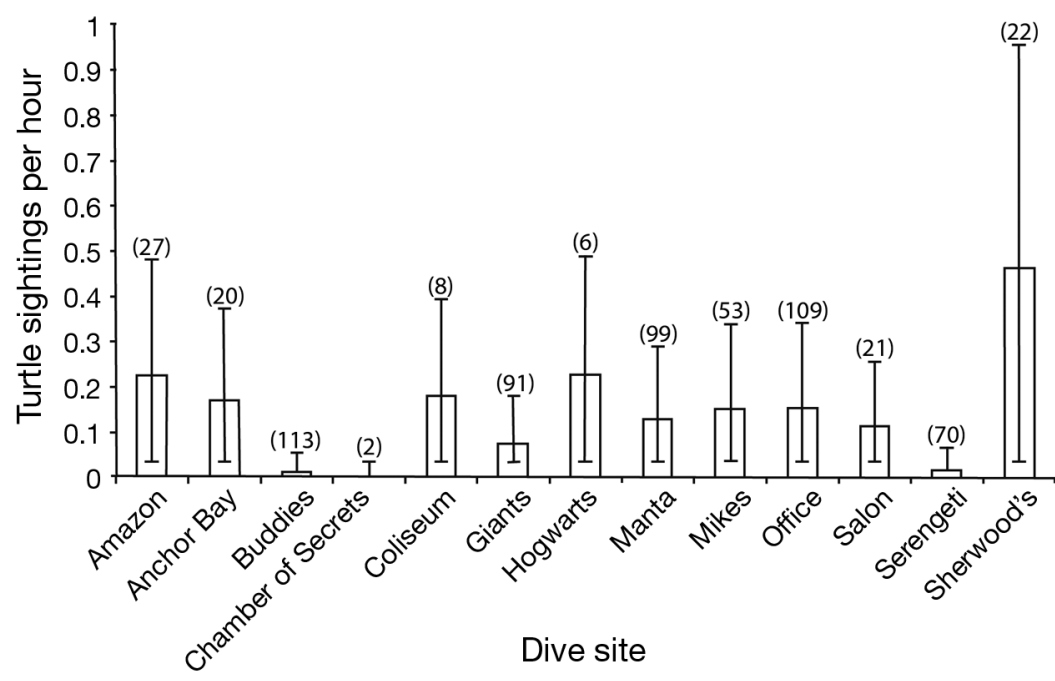

Fig. 3. Turtle sightings per hour per dive site (mean $\pm \mathrm{SE}$ ) from the logbook data set. Total numbers of dives per site (n) are displayed above the error bars ground for loggerhead (Gove \& Magane 1995) and leatherback sea turtles (Louro et al. 2006). The observed species composition ratios are compatible with our expectations and suggest that volunteers have a reasonable ability to identify the turtles to species level. The abundance of loggerhead sea turtles is consistent with them being the predominant nesting species in the study area (Gove \& Magane 1995). The relatively high ratio of green sea turtles suggests that the study area is important foraging habitat for the species, many of which nest in northern Mozambique and in limited numbers further north in Inhambane province (Bazaruto Archipelago) (Hughes 1971, Costa et al. 2007, Garnier et al. 2012). Additionally, approximately $500 \mathrm{~km}$ to the east of the study site, the island of Europa hosts the largest documented green turtle rookery in the southwestern Indian Ocean. Although the Madagascan coast is thought to be the primary foraging area for Europa green turtles, it is likely that some of the turtles seen in Mozambique are part of this stock, which still has to be investigated in future studies (Lauret-Stepler et al. 2007).

The CL data were sufficient to indicate basic population structure. The varied size data reported suggest a mixed age structure of the Tofo Beach population. Estimates of CL were recorded in $45 \%$ of turtle sightings from the dedicated survey data set, with most individuals (irrespective of species) estimated to be $71-100 \mathrm{~cm} \mathrm{CL}$, suggesting that the majority of turtles present are large immature or adult individuals. However, around $12 \%$ of estimates by divers were larger than the recorded maximum sizes for these species, particularly for loggerheads, for which $73 \%$ of estimates were biologically unlikely. Overestimates may be attributed to the magnifying effect of water in combination with limited training and experience. To overcome error in CL estimates, a subsample of turtles at each site could be measured and then validated by laser photogrammetry (Marshall et al. 2011, Rohner et al. 2011). Alternatively, participants could complete a training programme using objects of known size to improve accuracy of length estimates (Darwall \& Dulvy 1996). Although beneficial, laser photogrammetry and in-water size estimation training programs would also add complexity for participants, and training and maintenance of consistency may be problematic in an environment with a
Species composition was consistent between data sets, with loggerhead sea turtles the most abundant, followed by green turtles. Sightings of hawksbill, leatherback and olive ridley turtles were reported less frequently, rarely and not at all, respectively. Southern Mozambique is an important nesting 
largely transient workforce. Overall we found that the size estimate data set from the dedicated surveys was robust enough to address our specific research question regarding basic population structure.

\section{Lessons learned for using recreational divers to monitor sea turtles}

Although the majority of our citizen scientists were professionals within the SCUBA diving industry, most lacked strong marine turtle species identification skills. Thus, although the logbooks were completed by dive professionals the majority of entries did not contain species identifications. A large proportion of the dedicated surveys were completed by dive centre $\mathrm{D}$, which had an ongoing partnership with marine conservation volunteers. Through this program volunteers received species identification training, which contributed to the $97 \%$ of dedicated surveys that were assigned species records. Thus, if species identification training, such as that from the dedicated surveys, was delivered to dive staff compiling logbook entries we could expect a higher rate of records to be assigned to species level. The dedicated survey data suggests that some additional training is required to ensure correct identification between green and hawksbill turtles. We suspect this as high rates of hawksbill sea turtles were reported in the dedicated surveys, which was not consistent with the species ratios observed by the authors or other researchers based locally (J. L. Williams and S. J. Pierce unpubl. data). This likely suggests that participants were unable to easily distinguish between hawksbill and green turtles, particularly in juvenile stages. The challenge of requesting species identification from recreational SCUBA divers and non-scientific divers has been noted in the literature (Hickerson 2000, Houmeau 2007, Bell et al. 2008b). Even when other initiatives included data-confidence reporting criteria on survey forms, confidence in species identification was low (Bell et al. 2008b). Incorrect identification of species could be overcome in future projects using photographic records to accompany sighting reports (Hickerson 2000), and doing this would considerably increase the scientific utility of the study. Anecdotal information from study participants, and data from tracking studies elsewhere (Rees et al. 2013), suggest that individual turtles show fidelity to a particular site, and it cannot be known whether sightings were unique records of multiple individuals or repeat sightings of a single animal (Girondot 2010). The use of standardised pho- tos of facial scales would allow for more detailed information about individual animals (Goodman-Hall \& Braun McNeill 2013) (similar to a mark-recapture study), and possibly allow analysis of residency and movement between dive sites (Schofield et al. 2008, Brooks et al. 2011, Marshall \& Pierce 2012).

There is strong positive bias in the dedicated survey data because overall sample effort (e.g. total number of dive trips conducted) was not recorded. This data set was therefore not conducive to analysis of seasonal or longer-term trends. Underreporting of sampling effort is a problem frequently highlighted in citizen science programs (Roxburgh 2000, Barrett et al. 2002), and can to some extent be overcome by repeated requests for data collectors to report nonsightings (Bell et al. 2008b). Our requests for operator dive effort for periods sampled by citizen scientists were not successful, as has also been noted elsewhere (Lynch et al. 2004). Furthermore, effort and absence data are crucial in accounting for variable species detection rates that are typical of large opportunistic citizen science data sets (Fink et al. 2011, Van Strien et al. 2013). To address this problem in future citizen science projects, effort - in this case records of non-sightings - must be clearly documented over the course of the study. This could be overcome by establishing a regular or semi-regular reporting/recording process that is routinely monitored by scientific coordinators.

The greatest participation came from dive centre D, which filled in the dedicated surveys with ongoing collaboration from paying marine conservation volunteers, whose motivation, enthusiasm or incentive to participate may have influenced dive industry staff. We feel that success with this operator can be attributed to their partnership with a volunteer ecotourism marine project. By hosting this volunteer project, they had a monetary incentive to sustain data collection.

It is apparent that the other data collectors, the dive staff from dive centres A, B and C, did not consistently report all encounters (presence or absence). Maintaining enthusiasm among voluntary sampling parties is an ongoing issue for this type of methodology (Uychiaoco et al. 2005, Bell et al. 2008a, Finn et al. 2010). Both emotional attachment and intimate encounters with the study animals have been postulated as influential to both participants' enjoyment levels and overall citizen science programme success (Schänzel \& McIntosh 2000, Cousins et al. 2009). We feel these factors are important to consider when explaining the high variability in response rates in dedicated surveys. Given that turtle encounter rates 
throughout the sample period were relatively low (i.e. not guaranteed every dive trip), this may have affected participants' enthusiasm to report consistently.

Additionally, the high number of categories in the dedicated surveys $(n=17)$ may have prompted low consistency in reporting and high variability of response rates. Low reporting consistency is also hypothesised to be a result of the design of the dedicated surveys, as they relied on many participants to report sightings and thus individual accountability to report consistently was lost. We would recommend simplifying the survey criteria to respond to specific research questions. Participation amongst dive operators participating in the dedicated surveys was not homogeneous, and it seems conceivable that data quality and quantity may be linked with motivation or incentive to participate (e.g. Campbell \& Smith 2006). A suggested strategy to maintain enthusiasm and sustain volunteer-based projects is to demonstrate use and application of the collected data through information sessions and publications (Ryan et al. 2001). Overall, we found that the use of logbook data was most useful for evaluating trends in the long term. With this in mind, consistent reporting rates and sustained participation are key factors and further investigation is merited. Longterm dive records compiled by individuals or single dive centres are likely to be a valuable source of information for assessing basic trends of sea turtles and other charismatic marine animals in many areas.

The results of this survey provide the first insight into foraging sea turtle populations in Mozambique. Citizen science programs are highly dynamic; they require frequent training, data review and potential methodological changes during initial stages. Our experience suggests that working with a single dive centre is likely to be logistically easier, in terms of training (as training cycles can be accommodated to staff turnover), and will yield more consistent and usable results if regular engagement with participants is possible. However, our data show that working with multiple dive centres can produce viable data and allows for maximising sample effort.

Such a programme may also be most successful in locations where the survey animal is considered threatened or rare because this encourages reporting of encounters. Incorporating photographic records to validate species identification and individual animals will also strengthen monitoring programmes (Holmberg et al. 2009). A particularly appealing feature is that similar programmes can be designed, implemented and maintained with few direct costs, and thus could be widely adopted in developing nations and resource-restricted regions.
Acknowledgements. This is the 51st publication in the series from the All Out Africa (AOA) Research Unit. Sincere thanks go to the project coordinators (past and present) and marine volunteers from AOA who contributed to collection of the dedicated survey data, particularly J. Salmond, who initiated the project. Additionally, we thank L. Armstrong from Blue Footprints Eco Lodge and the Barra Lodge Dive Centre for providing the logbook data. Many thanks are extended to all the divers and dive staff from the 4 participating dive centres (Peri Peri Divers, Diversity Scuba, Liquid Adventures and Tofo Scuba) that contributed to the dedicated surveys. Idea Wild supported this project by providing underwater and laser photogrammetry equipment to advance the data collection methods. Casa Barry Lodge also provided in-kind support to in-country researchers over the duration of this project.

\section{LITERATURE CITED}

Barrett N, Edgar G, Morton A (2002) Monitoring of Tasmanian inshore reef ecosystems. An assessment of the potential for volunteer monitoring programs and a summary of changes within the Maria Island Marine Reserve from 1992-2001. Tasmanian Aquaculture and Fisheries Institute Technical Report Series 10, University of Tasmania

Bell S, Marzano M, Cent J, Kobierska H and others (2008a) What counts? Volunteers and their organisations in the recording and monitoring of biodiversity. Biodivers Conserv 17:3443-3454

Bell CD, Blumenthal JM, Austin TJ, Ebanks-Petrie G, Broderick AC, Godley BJ (2008b) Harnessing recreational divers for the collection of sea turtle data around the Cayman Islands. Tourism Mar Environ 5:245-257

$>$ Bhattacharjee Y (2005) Ornithology. Citizen scientists supplement work of Cornell researchers. Science 308: 1402-1403

Bjorndal KA (1999) Foraging ecology and nutrition of sea turtles. In: Lutz P, Musick J (eds) The biology of sea turtles. CRC Press, Boca Raton, FL, p 199-231

Bonney R, Cooper CB, Dickinson J, Kelling S, Phillips T, Rosenberg KV, Shirk J (2009) Citizen Science: A developing tool for expanding science knowledge and scientific literacy. Bioscience 59:977-984

Bradford BM, Israel GD (2004) Evaluating volunteer motivation for sea turtle conservation in Florida. University of Florida, Agriculture Education and Communication Department, Institute of Agriculture and Food Sciences, Gainesville, FL

Brooks K, Rowat D, Pierce SJ, Jouannet D, Vely M (2011) Seeing spots: photo-identification as a regional tool for whale shark identification. Western Indian Ocean J Mar Sci 9:185-194

Campbell LM, Smith C (2006) What makes them pay? Values of volunteer tourists working for sea turtle conservation. Environ Manage 38:84-98

Chou LM (1994) Living coastal resources of Southeast Asia: management through continuing education by institution of higher learning. Aquat Conserv 4:179-184

> Conrad CC, Hilchey KG (2011) A review of citizen science and community-based environmental monitoring: issues and opportunities. Environ Monit Assess 176:273-291

> Cornwell ML, Campbell LM (2012) Co-producing conservation and knowledge: citizen-based sea turtle monitoring in North Carolina, USA. Soc Stud Sci 42:101-120 
Costa A, Motta H, Pereira MAM, Videira EJS, Louro CMM, João J (2007) Marine turtles in Mozambique: the development of an effective conservation and management programme. Mar Turtle Newsl 117:1-11

> Cousins JA, Evans J, Sadler JP (2009) 'I've paid to observe lions, not map roads!' - an emotional journey with conservation volunteers in South Africa. Geoforum 40: 1069-1080

Crall AW, Newman GJ, Stohlgren TJ, Holfelder KA, Graham J, Waller DM (2011) Assessing citizen science data quality: an invasive species case study. Conserv Lett 4: 433-442

> Darwall WRT, Dulvy NK (1996) An evaluation of the suitability of non-specialist volunteer researchers for coral reef fish surveys, Mafia Island Tanzania. Biol Conserv 78:223-231

Eaton C, McMichael E, Witherington B, Foley A, Hardy R, Meylan A (2008) In-water sea turtle monitoring and research in Florida: review and recommendations. NOAA Tech Memo NMFS-OPR-38, US Dept of Commerce, St Petersburg, FL

Eckert KL (1999) Designing a conservation program. In: Bjorndal KA, Abreu-Grobois FA, Donnelly (eds) Research and management techniques for the conservation of sea turtles. IUCN/SSC Marine Turtle Specialist Group Publication No 4, p 6-8

Ehrhart LM, Ogren LH (1999) Studies in foraging habitats; capturing and handling turtles. In: Bjorndal KA, AbreuGrobois FA, Donnelly (eds) Research and management techniques for the conservation of sea turtles. IUCN/SSC Marine Turtle Specialist Group Publication No 4, p 61-64

Ellis C (2003) Participatory environmental research in tourism: a global view. Tourism Recr Res 28:45-55

Fink D, Hochack WM, Zuckerberg B, Kelling ST (2011) Modeling species distribution dynamics with SpatioTemporal Exploratory Models: discovering patterns and processes of broad-scale avian migrations. Procedia Environ Sci 7:50-55

Finn PG, Udy NS, Baltais SJ, Price K, Coles L (2010) Assessing the quality of seagrass data collected by community volunteers in Moreton Bay Marine Park, Australia. Environ Conserv 37:83-89

Foster-Smith J, Evans SM (2003) The value of marine ecological data collected by volunteers. Biol Conserv 113: $199-213$

> Garnier J, Hill N, Guissamulo A, Silva I, Witt M, Godley B (2012) Status and community-based conservation of marine turtles in the northern Querimbas Islands (Mozambique). Oryx 46:359-367

Girondot M (2010) Editorial: the zero counts. Mar Turtle Newsl 129:5-7

Goffredo S, Piccinetti C, Zaccanti F (2004) Volunteers in marine conservation monitoring: a study of the distribution of seahorses carried out in collaboration with recreational scuba divers. Conserv Biol 18:1492-1503

Goffredo S, Pensa F, Neri P, Orlandi A and others (2010) Unite research with what citizens do for fun: 'recreational monitoring' of marine biodiversity. Ecol Appl 20: 2170-2187

Goodman-Hall A, Braun McNeill J (2013) Inferring sea turtle recapture rates using photographic identification. Herpetol Rev 44:561-596

Gouveia C, Fonseca A, Câmara A, Ferreira F (2004) Promoting the use of environmental data collected by concerned citizens through information and communication technologies. J Environ Manage 71:135-154

Gove D, Magane S (1995) The status of sea turtle conservation in Mozambique. In: Humphrey SL, Salm RV (eds) Proceedings of the Western Indian Ocean training workshop and strategic planning session on sea turtles. IUCN/ UNEP, Sodwana Bay, p 2-8

Halusky JG, Seaman W, Strawbridge EW (1994) Effectiveness of trained volunteer divers in scientific documentation of artificial aquatic habitats. Bull Mar Sci 55:939-959

Hickerson EL (2000) Assessment and tracking resident, immature loggerheads (Caretta caretta) in and around the Flower Garden Banks, Northwest Gulf of Mexico. Masters thesis, Texas A\&M University, College Station, TX

Hodgson G (1999) A global assessment of human effects on coral reefs. Mar Pollut Bull 38:345-355

Holmberg J, Norman B, Arzoumanian Z (2009) Estimating population size, structure, and residency time for whale sharks Rhincodon typus through collaborative photoidentification. Endang Species Res 7:39-53

Houmeau V (2007) Influence du facteur alimentaire sur l'abondance des tortues imbriquees (Eretmochelys imbricata) dans l'archipel Guadeloupeen. Masters thesis, Université des Antilles et de la Guyane

Hughes G (1971) Preliminary report on the sea turtles and dugongs of Moçambique. Vet Mocambicana 4:43-84

Hussey NE, Stroh N, Klaus R, Chekchak T, Kessel ST (2011) SCUBA diver observations and placard tags to monitor grey reef sharks, Carcharhinus amblyrhynchos, at Sha'ab Rumi, The Sudan: assessment and future directions. J Mar Biol Assoc UK 93(2):1-10

Jaine FR, Couturier LIE, Weeks SJ, Townsend K, Bennett MB, Fiora K, Richardson AJ (2012) When giants turn up: sighting trends, environmental influences and habitat use of the manta ray Manta alfredi at a coral reef. PLoS ONE 7:e46170

Landry MS, Taggart CT (2010) 'Turtle watching' conservation guidelines: green turtle (Chelonia mydas) tourism in nearshore coastal environments. Biodivers Conserv 19: 305-312

Lauret-Stepler M, Bourjea J, Roos D, Pelletier D, Ryan PG, Ciccione S, Grizel H (2007) Reproductive seasonality and trend of Chelonia mydas in the SW Indian Ocean: a $20 \mathrm{yr}$ study based on track counts. Endang Species Res 3: $217-227$

Limpus CJ, Reed PC (1985) The green turtle, Chelonia mydas, in Queensland: a description of the population structure in a coral reef feeding ground. In: Grigg G, Shine R, Ehmann H (eds) Biology of Australasian frogs and reptiles. Royal Zoological Society of New South Wales, Mosman, p 47-52

> Lloyd P, Plagányi ÉE, Weeks SJ, Magno-Canto M, Plagányi G (2012) Ocean warming alters species abundance patterns and increases species diversity in an African subtropical reef-fish community. Fish Oceanogr 21:78-94

> Lorenzo B, Ilaria V, Sergio R, Stefano S, Giovanni S (2011) Involvement of recreational scuba divers in emblematic species monitoring: the case of Mediterranean red coral (Corallium rubrum). J Nat Conserv 19:312-318

Louro CMM, Pereira MAM, Costa ACD (2006) Report on the conservation status of marine turtles in Mozambique. Ministerio para a Coordenação da Ação Ambiental, Maputo

Lynch TP, Wilkinson E, Melling L, Hamilton R, MacReady A, Feary S (2004) Conflict and impacts of divers and anglers in a marine park. Environ Manage 33:196-211 
Marshall AD, Pierce SJ (2012) The use and abuse of photographic identification in sharks and rays. J Fish Biol 80: 1361-1379

Marshall AD, Dudgeon CL, Bennett MB (2011) Size and structure of a photographically identified population of manta rays Manta alfredi in southern Mozambique. Mar Biol 158:1111-1124

Miller-Rushing A, Primack R, Bonney R (2012) The history of public participation in ecological research. Front Ecol Environ 10:285-290

Mumby PJ, Harborne AR, Raines PS, Ridley JM (1995) A critical assessment of data derived from Coral Cay conservation volunteers. Bull Mar Sci 56:737-751

Obura DO, Church JE, Gabrié C (2012) Assessing marine world heritage from an ecosystem perspective: the Western Indian Ocean. World Heritage Centre, United Nations Education, Science and Cultural Organization (UNESCO), Paris

Pattengill-Semmens CV, Semmens BX (2003) Conservation and management applications of the REEF volunteer fish monitoring program. Environ Monit Assess 81:43-50

Paulos E (2009) Designing for doubt: citizen science and the challenge of change. In: Engaging data: First International Forum on the Application and Management of Personal Electronic Information. October 12-13, Cambridge, MA

Pereira MAM, Videira EJS, Narane DA, Louro CMM (2010) Monitoring, tagging and conservation of marine turtles in Mozambique: 2009/10 Annual report. Associação para Investigação Costeira e Marinha (AICM), Maputo

Pierce SJ, Méndez-Jiménez A, Collins K, Rosero-Caicedo M, Monadjem A (2010) Developing a code of conduct for whale shark interactions in Mozambique. Aquat Conserv Mar Freshw Ecosyst 20:782-788

Rees AF, Margaritoulis D, Newman R, Riggall TE, Tsaros P, Zbinden JA, Godley BJ (2013) Ecology of loggerhead marine turtles Caretta caretta in a neritic foraging habitat: movements, sex rations and growth rates. Mar Biol 160:519-529

Rohner CA, Richardson JA, Marshall AD, Weeks SJ, Pierce SJ (2011) How large is the world's largest fish? Measuring whale sharks Rhincodon typus with laser photogrammetry. J Fish Biol 78:378-385

Rohner CA, Pierce SJ, Marshall AD, Weeks SJ, Bennett MB, Richardson AJ (2013) Trends in sightings and environmental influences on a coastal aggregation of manta rays and whale sharks. Mar Ecol Prog Ser 482:153-168

Roxburgh T (2000) Checking Reef Check in Tanzania. Reef Encounter 27:21

Ryan RL, Kaplan R, Grese RE (2001) Predicting volunteer commitment in environmental stewardship programmes. J Environ Plan Manage 44:629-648

Editorial responsibility: Matthew Godfrey, Beaufort, North Carolina, USA
Schänzel HA, McIntosh AJ (2000) An insight into the personal and emotive context of wildlife viewing at the Penguin Place, Otago Peninsula, New Zealand. J Sustainable Tourism 8:36-52

Schmitt EF, Sullivan KM (1996) Analysis of a volunteer method for collecting fish presence and abundance data in the Florida Keys. Bull Mar Sci 59:404-416

Schofield G, Katselidis KA, Dimopoulos P, Pantis JD, Hays GC (2006) Behaviour analysis of the loggerhead sea turtle Caretta caretta from direct in-water observation. Endang Species Res 2:71-79

Schofield G, Katselidis K, Dimopoulos P, Pantis JD (2008) Investigating the viability of photo-identification as an objective tool to study endangered sea turtle populations. J Exp Mar Biol Ecol 360:103-108

Seminoff JA, Resendiz A, Nichols WJ (2002) Home range of green turtles Chelonia mydas at a coastal foraging area in the Gulf of California, Mexico. Mar Ecol Prog Ser 242: 253-265

Shirk JL, Ballard HL, Wilderman CC, Phillips T and others (2012) Public participation in scientific research: a framework for deliberate design. Ecol Soc 17:29-46

> Silvertown J (2009) A new dawn for citizen science. Trends Ecol Evol 24:467-471

> Sims M, Bjorkland R, Mason P, Crowder LB (2008) Statistical power and sea turtle nesting beach surveys: How long and when? Biol Conserv 141:2921-2931

Teleki KA (2012) Power of the people? Aquat Conserv 22:1-6

Tibiriçá Y, Birtles A, Valentine P, Miller DK (2011) Diving tourism in Mozambique: an opportunity at risk? Tourism Mar Environ 7:141-151

Uychiaoco AJ, Arceo HO, Green SJ, La Cruz MTD, Gaite PA, Aliño PM (2005) Monitoring and evaluation of reef protected areas by local fishers in the Philippines: tightening the adaptive management cycle. Biodivers Conserv 14:2775-2794

- Van Buskirk J, Crowder LB (1994) Life-history variation in marine turtles. Copeia 66-81

Van Strien AJ, Van Swaay CAM, Termaat T (2013) Opportunistic citizen science data of animal species produce reliable estimates of distribution trends if analysed with occupancy models. J Appl Ecol 50:1450-1458

- Ward-Paige CA, Lotze HK (2011) Assessing the value of recreational divers for censusing elasmobranchs. PLoS ONE 6:e25609

> Ward-Paige CA, Pattengill-Semmens C, Myers RA, Lotze HK (2011) Spatial and temporal trends in yellow stingray abundance: evidence from diver surveys. Environ Biol Fishes 90:263-276

Wilson C, Tisdell C (2001) Sea turtles as a non-consumptive tourism resource especially in Australia. Tour Manage $22: 279-288$

Submitted: November 28, 2013; Accepted: August 29, 2014 Proofs received from author(s): November 11, 2014 